\title{
Potential of New-Generation Electron Beam Technology in Interface Modification of Cold and HVOF Sprayed MCrAlY Bond Coats
}

\author{
J. Cizek, M. Matejkova, J. Kouril, J. Cupera, and I. Dlouhy \\ Institute of Materials Science and Engineering, NETME Centre, Brno University of Technology, 61669 Brno, Czech Republic \\ Correspondence should be addressed to J. Cizek; cizek@fme.vutbr.cz
}

Received 4 September 2015; Revised 24 November 2015; Accepted 25 November 2015

Academic Editor: Ming-Xing Zhang

Copyright (c) 2016 J. Cizek et al. This is an open access article distributed under the Creative Commons Attribution License, which permits unrestricted use, distribution, and reproduction in any medium, provided the original work is properly cited.

\begin{abstract}
Electron beam (EB) technology treatment was carried out on CoNiCrAlY bond coats deposited on Inconel substrates via cold spray and HVOF techniques in dissimilar thicknesses. Such treatment was carried out with regard to the final materials microstructure, composition, surface roughness, and the quality of the coating-substrate interface. Following a multiple-step optimization of the processing parameters (such as beam pattern configuration, accelerating voltage, longitudinal speed, and multiple beam incidence), two final EB modifications were carried out on both coating types. It was found that the optimized EB treatment could lead to a significant alteration of the interface from a distinctive divide into smooth chemical and structural transition between the materials, significant decrease in surface roughness and porosity, and changes in mechanical properties (increase in Young's modulus and decrease in hardness of the coating).
\end{abstract}

\section{Introduction}

New-generation electron beam treatment [1] of materials has been successfully used in various applications such as deep welding [2,3], (selective) melting [4-6], cladding and precipitation [7], heat-treatment and recrystallization, synthesis [8], structure and properties modification [9-11], or, for example, hardening [12, 13]. Among the advantages of the method the major ones include nonoxidizing environment, rapid and simultaneous processing, versatility, and high thermal localized input into the material.

The modification of structure related to joining of dissimilar materials (often via welding) is primarily based on rapid thermal input and (selective) melting of one or both of the components. Such processing involves materials in liquid phase which might affect the resulting microstructure. However, at lower, precisely positioned, and localized heat inputs (at, e.g., lower beam currents, faster beam longitudinal speeds), joining of two dissimilar metals could be reached via small-scale melting and a catalyzed diffusion (while suppressing Kirkendall effect [14]).
Inherently resistant to elevated temperatures, MCrAlY (frequently, $\mathrm{M}=\mathrm{Co}, \mathrm{Ni}$, or both) coatings are commonly used as bond coats for ceramic-based thermal barrier coatings (TBC, often $\mathrm{ZrO}_{2}+\mathrm{Y}_{2} \mathrm{O}_{3}$ ) topcoats. Their composition is similar to that of superalloys used at high temperatures but is generally richer in $\mathrm{Al}$ and $\mathrm{Cr}$ to promote a formation of a protective oxide scale. Afterward, such compositional difference acts as a driving force for the interdiffusion between the substrate and the coating. As a result, microstructural changes at the interface are generated in both the substrate and the coating, which may lead to a formation of detrimental phases, such as sigma-phases, Laves phases, brittle carbides, and other coating imperfections like voids and porosity. Eventually, these may lead to changes in the mechanical properties and a potential failure [15-17].

Cold spray [18-21] and HVOF [22-24] are two thermal spray methods used to deposit bond coatings $[25,26]$ onto Inconel substrates. The respective advantages of the methods include lower thermal input and supersonic deposition of the particles, leading to a very low porosity, coherent microstructure, lower oxidation of the materials, and superior adhesion 


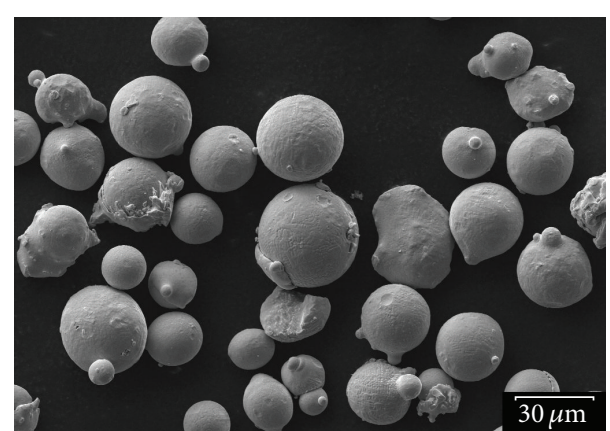

Figure 1: Morphology of the used CoNiCrAlY powder.

to the substrates (as, e.g., compared to plasma spray or wirearc deposition), which are parameters of utmost importance towards the functionality of such coating types.

The main motivation of the study was manifesting the feasibility of the coating/substrate interface modification using optimized EB treatment in order to achieve interface with smooth (chemical) transition (to avoid the commonly observed detrimental effects), as well as improving the adherence between the two. The first demonstration of the EB remelting potential was given by Ando and coworkers [6] whereby $\mathrm{Nb}_{3} \mathrm{Al} 300 \mu \mathrm{m}$ coatings cold sprayed onto $\mathrm{Cu}$ substrates were modified using the beam heat input. In our study, CoNiCrAlY powder was deposited onto Inconel 718 Ni-based superalloy substrates via cold spray and HVOF methods. Modification of the initial structure and interface quality via optimized EB treatment was then carried out.

\section{Materials and Methods}

Commercially available CoNiCrAlY powder (Diamalloy 4700, HC Starck, Germany) was used as the feedstock. The powder exhibited spherical morphology (Figure 1) and the particle sizes were measured as $-69.3+14.5 \mu \mathrm{m}$ (D10-D90) by laser diffraction; that is, the powder was proven suitable for deposition using both methods. As substrates, Inconel 718 sheets were cut into $40 \times 20 \times 2 \mathrm{~mm}^{3}$ coupons. To prove the ability of the EB technology for materials treatment under different conditions, two different technologies (PCS1000 cold spray, Plasma Giken, Japan, and JP5000 HVOF, Praxair Tafa, USA) were used for the bond coats deposition. To further demonstrate the EB variability, the coatings were produced at highly dissimilar thicknesses (CS-A and HVOFA in Table 1).

Electron beam (K26, Probeam, Germany) treatment of the samples was then carried out $\left(1.4 \times 10^{-8}\right.$ bar vacuum). The aim of the treatment was to induce microstructure changes of the MCrAlY-substrate interface; that is, it was necessary to optimize the depth of energy input into the components. Preliminary optimization steps were carried out to determine the optimal treatment conditions for both coating types. In the steps, parameters such as acceleration voltage, beam current, longitudinal speed, and beam oscillation (single versus multiple beam incidence, its pattern, and frequency, Figure 2) were modified and the obtained structures were

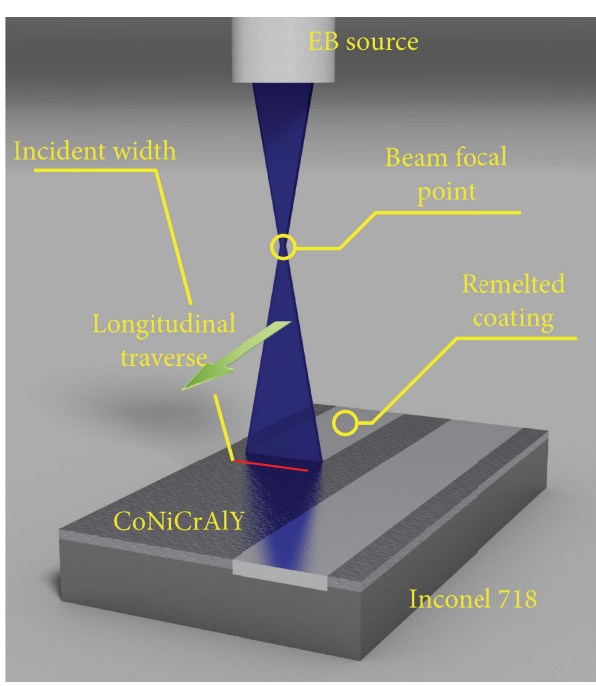

FIGURE 2: Schematics of EB surface remelting.

studied [27]. Subsequently, two final modifications were selected based on the quality of microstructure, penetration depth, and interface features and performed to either of the layers (single beam, linear beam pattern defocused to $8 \mathrm{~mm}$ incident width, $500 \mathrm{~Hz}$ frequency, Table 2).

The as-sprayed (set A) and EB modified (sets B, C) materials were then investigated. The microstructure and interface character was studied using SEM and additional images further served for determination of the porosity of the CoNiCrAlY material (image analysis method, at least 5 images per measurement under 400x and 1000x SEM magnifications). The surface roughness $\left(R_{a}\right)$ was measured using a contact TR200 (TimeGroup, China) profile meter. Chemical and phase analyses were carried out using EDX mapping and XRD. Mechanical properties (instrumented hardness $H_{\mathrm{IT}}$ and moduli $E_{\mathrm{IT}}$ ) were measured using nanoindentation techniques $\left(\mathrm{NHT}^{2}\right.$ Nanoindentation Tester, CSM Instruments, Switzerland). For the measurements, Oliver-Pharr methodology $(98 \%, 40 \%)$ under maximum load of $70 \mathrm{mN}$ was used, and at least eight measurements per set were carried out.

\section{Results and Discussion}

The microstructure of the samples prior to and after the EB modifications is shown in Figure 3. Individual splats could be partially distinguished in the cold sprayed CoNiCrAlY structure (CS-A) with negligible amount of intersplat voids, leading to a low porosity of $0.13 \%$ (Table 1 ). The splats structure consists of a distinctive two-phase eutectic pattern formed by fine $\mathrm{NiAl}$ intermetallic in $\mathrm{Ni}-(\mathrm{Co}, \mathrm{Cr})$ solid solution matrix, identical to the composition of the feedstock powder. The intermetallic phase was not detected in the XRD spectra as $100 \% \mathrm{Ni}-(\mathrm{Co}, \mathrm{Cr})$ phase content was measured (Table 3$)$. The interface between the coating and the substrate is apparent and the materials appear well bonded. The surface roughness of the as-sprayed set $\left(R_{a}=11.7 \mu \mathrm{m}\right)$ is a consequence of the individual spherical-shaped particles that are seen protruding from the topmost material. 
TABLE 1: Properties of as-sprayed and EB treated samples.

\begin{tabular}{|c|c|c|c|c|c|}
\hline Sample & $\begin{array}{c}\text { Thickness } \\
(\mu \mathrm{m})\end{array}$ & $\begin{array}{l}\text { Young's modulus } \\
(\mathrm{GPa})\end{array}$ & $\begin{array}{l}\text { Instrumented hardness } \\
(\mathrm{GPa})\end{array}$ & $\begin{array}{c}\text { Porosity } \\
(\%)\end{array}$ & $\begin{array}{c}\text { Roughness } \\
\left(R_{a}, \mu \mathrm{m}\right)\end{array}$ \\
\hline CS-A & 756 & $8008 \pm 285$ & $171 \pm 14$ & 0.13 & 11.7 \\
\hline CS-B & 1197 & $5114 \pm 239$ & $190 \pm 5$ & 0.05 & 2.7 \\
\hline CS-C & 924 & $5416 \pm 266$ & $206 \pm 6$ & 0.02 & 2.1 \\
\hline HVOF-A & 40 & $8175 \pm 325$ & $174 \pm 8$ & 5.81 & 6.1 \\
\hline HVOF-B & 37 & $6821 \pm 434$ & $184 \pm 11$ & 4.15 & 5.7 \\
\hline HVOF-C & 43 & $4641 \pm 57$ & $186 \pm 7$ & 1.67 & 3.5 \\
\hline
\end{tabular}

TABLE 2: Annotation of the samples and optimized EB parameters (set A denotes as-sprayed reference set, i.e., with no electron beam treatment).

\begin{tabular}{lccc}
\hline Annotation & $\begin{array}{c}\text { Accelerating } \\
\text { voltage } \\
(\mathrm{kV})\end{array}$ & $\begin{array}{c}\text { Beam } \\
\text { current } \\
(\mathrm{mA})\end{array}$ & $\begin{array}{c}\text { Longitudinal } \\
\text { speed } \\
\left(\mathrm{mm} \cdot \mathrm{s}^{-1}\right)\end{array}$ \\
\hline CS-A & - & - & - \\
CS-B & 120 & 14 & 15 \\
CS-C & 120 & 18 & 20 \\
HVOF-A & - & - & - \\
HVOF-B & 120 & 3 & 20 \\
HVOF-C & 120 & 4 & 20 \\
\hline
\end{tabular}

The optimized treatment of the CS sets led to substantial changes in the microstructure of the sprayed material. Individual splats are no longer visible in the layer and the eutectic structure was transformed partially as a distinct coarsening of the NiAl precipitates was observed (Figure 3). This result was further confirmed by XRD method as the phase content of $18,3 \%$ and $19,8 \%$ NiAl was measured for CS-B and CS$\mathrm{C}$ sets, respectively (Table 3 ). Such changes are probably a consequence of the beam heat input closely above the material $T_{m}$ (melting temperature). No detrimental phases (e.g., Laves phases, $\sigma$-phases, and precipitated carbides) were found in the measured spectra (both CS and HVOF). The chemical composition changed slightly owing to two phenomena: diffusion of elements between the layer and the Inconel substrate (mainly $\mathrm{Co}, \mathrm{Ni}, \mathrm{Fe}$, and $\mathrm{Nb}$ ) and formation of $<10 \mu \mathrm{m}$ thin $\mathrm{Al}_{2} \mathrm{O}_{3}, \mathrm{Y}_{2} \mathrm{O}_{3}$ oxide shell at the surface (thereby reducing $\mathrm{Al}$ and $\mathrm{Y}$ content in the bulk). Due to the changes, the porosity was completely eliminated in the EB treatment (as also observed in [28]) and a marked surface roughness reduction was observed (Table 1 ). The structural changes were more pronounced in case of the set $B$, that is, under the slower beam longitudinal speed. Due to the interdiffusion of the two components, the interface advanced into the substrate region markedly. The previously distinctive layersubstrate interface attained a transient character (illustrated in Figure 4 for CS-B sample), completely obliterating any interfacial voids or microcracks, thereby improving its quality significantly. Further to that, such change could prospectively lead to a significant increase in the respective adhesion of the two components (currently under measurement). This effect
TABLE 3: Results of phase analyses obtained using XRD method (wt\%).

\begin{tabular}{lccc}
\hline & $\mathrm{Ni}-(\mathrm{Co}, \mathrm{Cr})$ & $\mathrm{NiAl}$ & $\mathrm{Y}_{2} \mathrm{O}_{3}$ \\
\hline Powder & 68,9 & 31,1 & \\
CS-A & 100,0 & & \\
CS-B & 70,0 & 18,3 & 11,6 \\
CS-C & 74,0 & 19,8 & 6,3 \\
HVOF-A & 80,5 & 19,5 & \\
HVOF-B & 82,3 & 17,7 & \\
HVOF-C & 81,9 & 18,1 & \\
Substrate & 100,0 & & \\
\hline
\end{tabular}

was more pronounced for the set CS-B as well. In the study [6], the interface appeared impaired after the EB treatment, possibly a consequence of the coating delamination from the substrate. This was also observed in our study during preliminary testing at high beam powers. Given the difference to our B, C sets, it could probably be concluded that the two modes (delamination versus interdiffusion) may be triggered by an optimized selection of the EB treatment parameters.

The thinner as-sprayed HVOF layers consisted of splats structure with some intersplat chained voids. The individual splats exhibited similar structure as those of the CS set, that is, NiAl phase in the Ni-(Co, Cr) matrix. This time, the XRD method detected the NiAl content as $20 \%$ (Table 3 ) and some negligible oxidation $(\leq 0.3 \%)$. The interface quality appeared slightly impaired due to a presence of connected porosity. The smaller surface roughness of $R_{a}=6.1 \mu \mathrm{m}$ (cf. CS-A) is probably a consequence of the feedstock particles (partial) melting during the HVOF deposition.

The EB treatment in case of both $\mathrm{B}, \mathrm{C}$ conditions led to an improvement of the interfacial features. Unlike in CS samples, the EB treatment of HVOF samples retained the eutectic two-phase structure within the individual splats; that is, no coarsening of $\mathrm{NiAl}$ precipitates was observed. The difference could be probably attributed to the different EB currents used for the treatments of different thicknesses of materials $(765 \mu \mathrm{m}$ versus $40 \mu \mathrm{m})$, resulting in different rates of heat dissipation. Negligible changes in chemical and phase composition were recorded via EDX and XRD methods for HVOF EB-treated samples. The change in the beam current from $3 \mathrm{~mA}$ (HVOF-B) to $4 \mathrm{~mA}$ (HVOF-C) triggered additional changes in the material: reduction in 

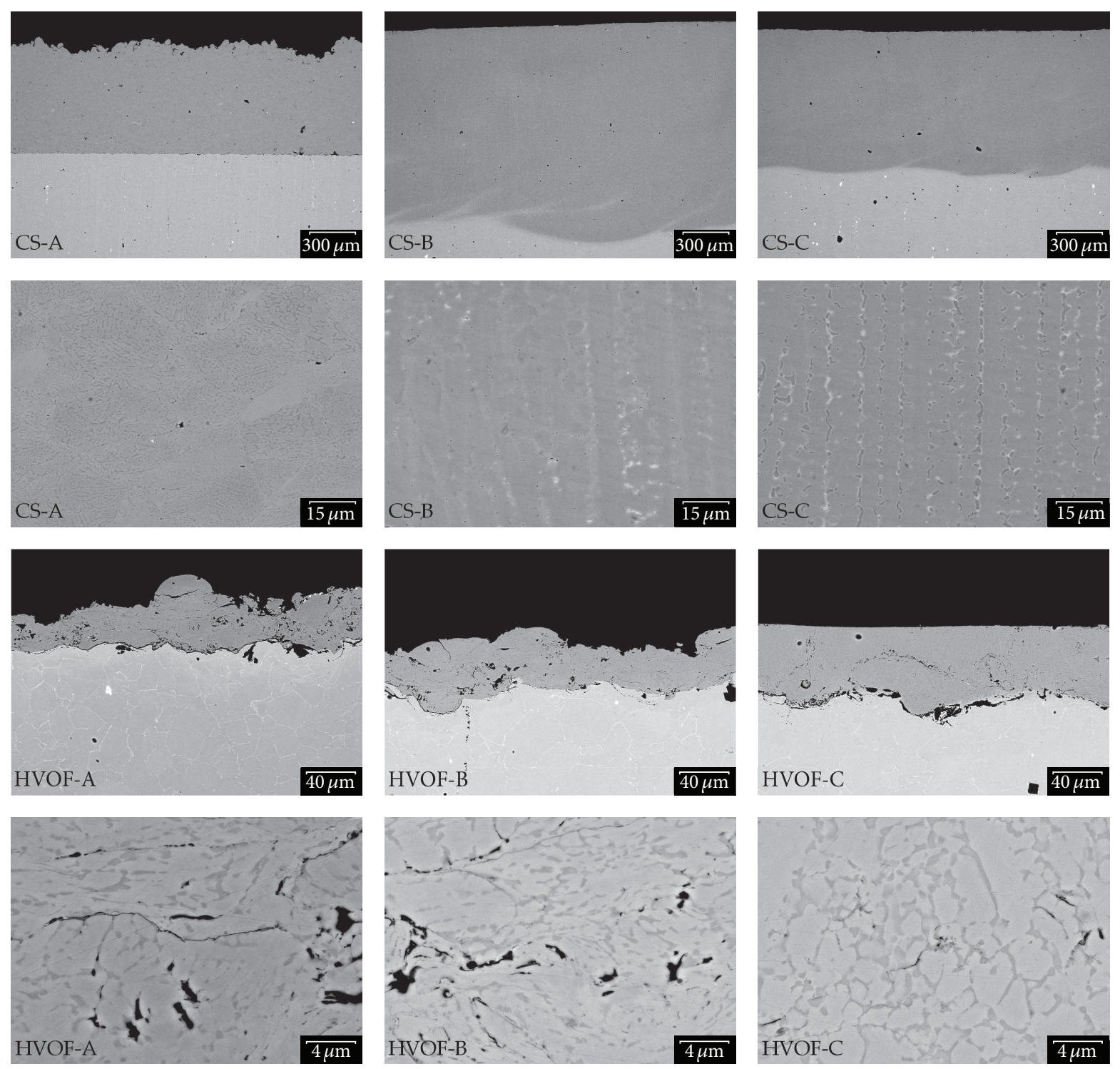

FIGURE 3: Interface and surface features and detailed microstructure of as-sprayed and EB modified samples.

the porosity and obliteration of the surface roughness, more pronounced for HVOF-C set, whereby the porosity levels reached as low as $1.67 \%$ and the roughness was obliterated to $60 \%$ of its as-sprayed value (Table 1 ). The difference between the treatments probably stems from the fact that the HVOF-C material underwent increased partial melting within the treatment. This statement was later confirmed by the differences observed in the EDX mapping of the element distribution in both the substrate and the deposited CoNiCrAlY. Of the mapped elements, three were selected to illustrate the diffusion effect: Co (nonpresent in Inconel 718 substrate), $\mathrm{Fe}$, and $\mathrm{Nb}$ (nonpresent in CoNiCrAlY). In case of HVOF-B treatment, the interface remained almost intact and the amount of interdiffused elements is negligible. The HVOF-C treatment evidently brought along diffusing of the two materials, as shown in the mapping images (Figure 5).
This further resulted in a higher quality interface, as recorded in SEM observations.

The mixing with the substrate material also introduced marked changes in the mechanical properties of the materials. The substrate hardness and elastic moduli (measured as $H_{\mathrm{IT}}=3747 \mathrm{GPa}$ and $E_{\mathrm{IT}}=162 \mathrm{GPa}$ ) were lower than those of the as-sprayed CS-A and HVOF-A samples (Table 1). The EB treatment brought along a significant decrease in the measured hardness of the layer. This could be probably caused by three phenomena, recrystallization of the structure (i.e., reduction in dislocations density by a factor of up to $10^{2}$ at temperatures close to $T_{m}$ ), recovery of compressive residual stresses that have arisen from the deposition process, and the diffusion of relatively soft iron, whose distribution was not allocated into precipitates, but it was rather evenly distributed instead. An increase of about $6 \%-20 \%$ in the elastic 

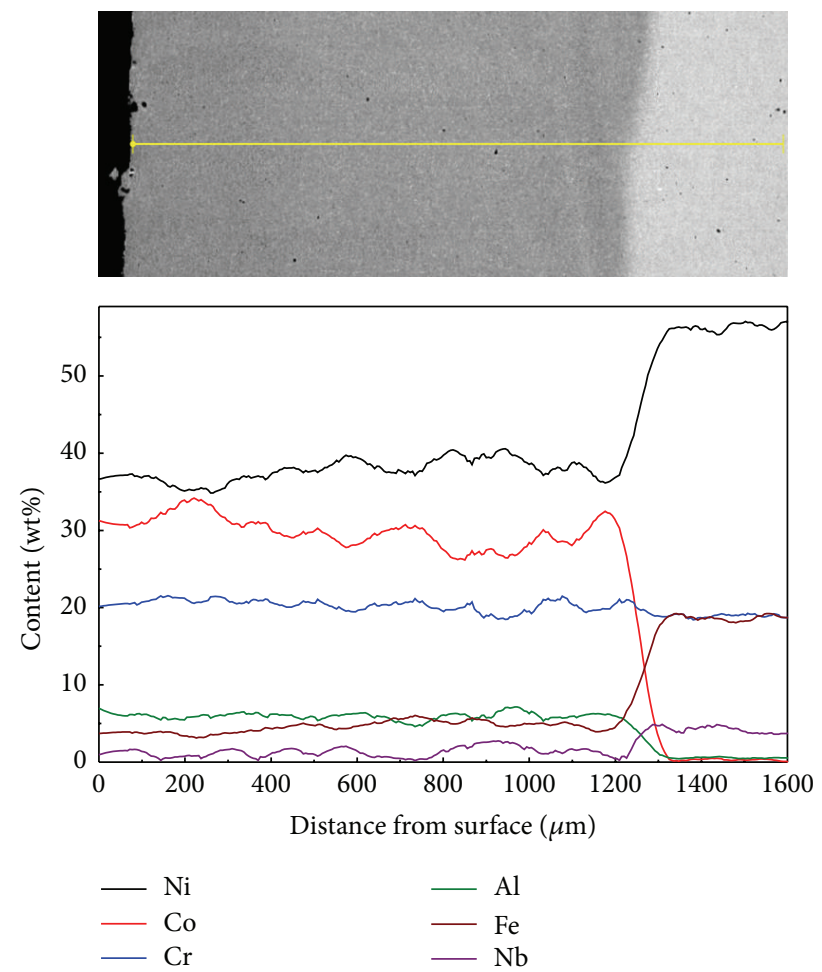

FIgURE 4: Transient character of the interface in EB treated CS samples measured by linear EDX method.
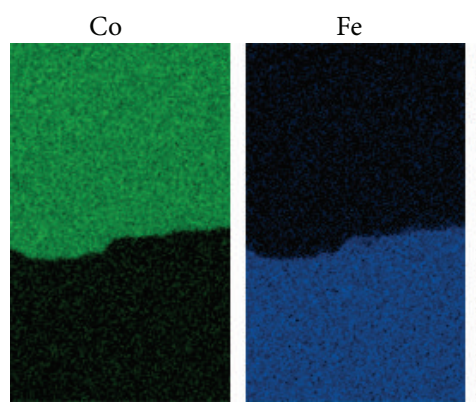

(a)
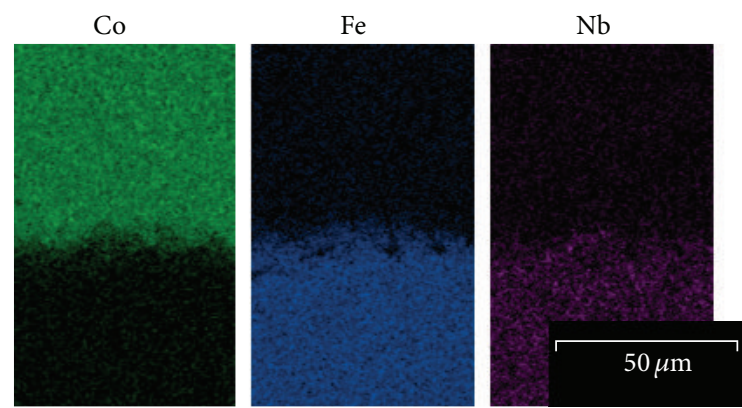

(b)

FIGURE 5: Element mapping differences in the interface character after EB treatment under HVOF-B (a) and HVOF-C (b) conditions. modulus was also recorded. The increase could have been caused by changes in the atomic bonds in the lattice due to the interdiffusion.

\section{Conclusions}

The potential of new-generation electron beam technology treatment on the surface and interface modification of CoNiCrAlY bond coats on Inconel substrates was demonstrated. Through the treatment, a good quality transient interface was obtained for coatings deposited via cold spray and HVOF technologies at dissimilar thicknesses. The changes in the microstructure and chemical gradient (from a distinct step into transient) of the interface could prevent the formation of detrimental phases upon subjecting the component to elevated temperatures. Further to that, porosity of the bond coats was reduced in the treatment and the initial splats structure was not retained, thereby producing bulk-like material.

Apart from the diffusion of elements ( $\mathrm{Fe}, \mathrm{Nb}, \mathrm{Mo}$, and $\mathrm{Ti}$ ) between the two counterparts, no other chemical changes were detected after the EB treatment, a consequence of the high EB processing vacuum. Phase composition indicated the heat input closely to $T_{m}$ levels modified the structure slightly, with coarsening of the eutectic structure detected for thick CS compacts. A change in mechanical properties (decrease in hardness of $\sim 17-43 \%$ and increase in elastic modulus of $\sim 7-$ $20 \%$ ) caused by diffusion of the elements from the substrate was observed.

It could be concluded that the EB technology has shown a strong potential for modification of close-contact metals via enhanced diffusion without oxidation or other detrimental chemical, phase, or structural changes (e.g., formation of dendritic structure and detrimental phases). Considering these and its advantages over conventional laser treatment (i.e., beam splitting, parallel multiple processing, and high processing vacuum), the technology could be considered a promising technique for further processing of thick bulks.

\section{Conflict of Interests}

The authors declare that there is no conflict of interests regarding the publication of this paper.

\section{Acknowledgments}

The authors would like to thank Mr. Lukas Cenek for help in conducting the experimental work and Mr. Michal Cizek for providing the EB melting schematics. The works have been supported by the project NETME Centre PLUS (Lo1202), project of Ministry of Education, Youth and Sports under the "National Sustainability Programme."

\section{References}

[1] R. Zenker, A. Buchwalder, K. Rüthrich, W. Griesbach, and K. Nagel, "First results of a new duplex surface treatment for cast iron: electron beam remelting and plasma nitriding," Surface and Coatings Technology, vol. 236, pp. 58-62, 2013. 
[2] J. C. Sabol, C. J. Marvel, M. Watanabe, T. Pasang, and W. Z. Misiolek, "Confirmation of the $\omega$-phase in electron beam welded Ti-5Al-5V-5Mo-3Cr by high-resolution scanning transmission electron microscopy: an initial investigation into its effects on embrittlement," Scripta Materialia, vol. 92, pp. 15-18, 2014.

[3] J. Kim and Y. Kawamura, "Electron beam welding of the dissimilar Zr-based bulk metallic glass and Ti metal," Scripta Materialia, vol. 56, no. 8, pp. 709-712, 2007.

[4] T. Fujieda, H. Shiratori, K. Kuwabara et al., "First demonstration of promising selective electron beam melting method for utilizing high-entropy alloys as engineering materials," Materials Letters, vol. 159, pp. 12-15, 2015.

[5] M. A. Lodes, R. Guschlbauer, and C. Körner, "Process development for the manufacturing of $99.94 \%$ pure copper via selective electron beam melting," Materials Letters, vol. 143, pp. 298-301, 2015.

[6] T. Ando, A. Miyazoe, N. Hirota et al., "Direct production of $\mathrm{Nb}_{3} \mathrm{Al}$ superconducting coil by electron beam irradiation on a cold-sprayed cylinder," Surface and Coatings Technology, vol. 205, no. 7, pp. 1990-1994, 2010.

[7] D. Tomus, M. Qian, C. A. Brice, and B. C. Muddle, "Electron beam processing of $\mathrm{Al}-2 \mathrm{Sc}$ alloy for enhanced precipitation hardening," Scripta Materialia, vol. 63, no. 2, pp. 151-154, 2010.

[8] S. Kageyama, N. Tamon, J. Kugai et al., "Radiation induced synthesis of $\mathrm{PtCu} / \mathrm{C}$ nanoparticles using high-energy electron beam," Materials Letters, vol. 82, pp. 33-35, 2012.

[9] H. Su, J. Zhang, L. Liu, and H. Fu, "Preparation and microstructure evolution of directionally solidified $\mathrm{Al}_{2} \mathrm{O}_{3}$ /YAG/YSZ ternary eutectic ceramics by a modified electron beam floating zone melting," Materials Letters, vol. 91, pp. 92-95, 2013.

[10] T. Grosdidier, J. X. Zou, N. Stein, C. Boulanger, S. Z. Hao, and C. Dong, "Texture modification, grain refinement and improved hardness/corrosion balance of a FeAl alloy by pulsed electron beam surface treatment in the "heating mode," Scripta Materialia, vol. 58, no. 12, pp. 1058-1061, 2008.

[11] X. Zhao, T. Hashimoto, and P. Xiao, "Effect of the top coat on the phase transformation of thermally grown oxide in thermal barrier coatings," Scripta Materialia, vol. 55, no. 11, pp. 10511054, 2006.

[12] R. Zenker, G. Sacher, A. Buchwalder, J. Liebich, A. Reiter, and R. Häßler, "Hybrid technology hard coating-electron beam surface hardening," Surface and Coatings Technology, vol. 202, no. 4-7, pp. 804-808, 2007.

[13] D. Nam, J. Do, and S. Lee, "Improvement of hardness and fracture toughness of surface composites fabricated by highenergy electron-beam irradiation with $\mathrm{Fe}$-alloy powders and VC powders," Scripta Materialia, vol. 60, no. 8, pp. 695-698, 2009.

[14] A. D. Smigelskas and E. O. Kirkendall, "Zinc diffusion in alpha brass," Transactions of AIME, vol. 171, pp. 130-142, 1947.

[15] D. R. G. Achar, R. Munoz-Arroyo, L. Singheiser, and W. J. Quadakkers, "Modelling of phase equilibria in MCrAlY coating systems," Surface and Coatings Technology, vol. 187, no. 2-3, pp. 272-283, 2004.

[16] W. R. Chen, X. Wu, B. R. Marple, and P. C. Patnaik, "Oxidation and crack nucleation/growth in an air-plasma-sprayed thermal barrier coating with NiCrAlY bond coat," Surface and Coatings Technology, vol. 197, no. 1, pp. 109-115, 2005.

[17] W. R. Chen, X. Wu, B. R. Marple, D. R. Nagy, and P. C. Patnaik, "TGO growth behaviour in TBCs with APS and HVOF bond coats," Surface and Coatings Technology, vol. 202, no. 12, pp. 2677-2683, 2008.
[18] A. Papyrin, V. Kosarev, S. Klinkov, A. Alkimov, and V. Fomin, Cold Spray Technology, Elsevier, 2007.

[19] H. Assadi, F. Gärtner, T. Stoltenhoff, and H. Kreye, "Bonding mechanism in cold gas spraying," Acta Materialia, vol. 51, no. 15, pp. 4379-4394, 2003.

[20] J. Cizek, O. Man, P. Roupcova, K. Loke, and I. Dlouhy, "Oxidation performance of cold spray Ti-Al barrier coated $\gamma$ TiAl intermetallic substrates," Surface and Coatings Technology, vol. 268, pp. 85-89, 2015, 6th Rencontres Internationales de la Projection Thermique.

[21] J. Cizek, O. Kovarik, J. Siegl, K. A. Khor, and I. Dlouhy, "Influence of plasma and cold spray deposited Ti Layers on high-cycle fatigue properties of Ti6Al4V substrates," Surface and Coatings Technology, vol. 217, pp. 23-33, 2013.

[22] R. C. Tucker, ASM Handbook: Thermal Spray Technology, ASM International, 2013.

[23] C. Lyphout, P. Nylén, and L. Östergren, "Relationships between process parameters, microstructure, and adhesion strength of HVOF sprayed IN718 coatings," Journal of Thermal Spray Technology, vol. 20, no. 1-2, pp. 76-82, 2011.

[24] O. Kováŕík, J. Siegl, and Z. Procházka, "Fatigue behavior of bodies with thermally sprayed metallic and ceramic deposits," Journal of Thermal Spray Technology, vol. 17, no. 4, pp. 525-532, 2008.

[25] P. Richer, M. Yandouzi, L. Beauvais, and B. Jodoin, "Oxidation behaviour of CoNiCrAlY bond coats produced by plasma, HVOF and cold gas dynamic spraying," Surface and Coatings Technology, vol. 204, no. 24, pp. 3962-3974, 2010.

[26] Q. Zhang, C.-J. Li, C.-X. Li, G.-J. Yang, and S.-C. Lui, "Study of oxidation behavior of nanostructured NiCrAlY bond coatings deposited by cold spraying," Surface and Coatings Technology, vol. 202, no. 14, pp. 3378-3384, 2008.

[27] P. Gavendova, J. Cizek, J. Cupera, M. Hasegawa, and I. Dlouhy, "Microstructure modification of CGDS and HVOF sprayed CoNiCrAlY bond coat remelted by electron beam," Procedia Materials Science, In press.

[28] U. Dragos, M. Gabriela, B. Waltraut, and C. Ioan, "Improvement of the oxidation behaviour of electron beam remelted MCrAlY coatings," Solid State Sciences, vol. 7, no. 4, pp. 459-464, 2005. 

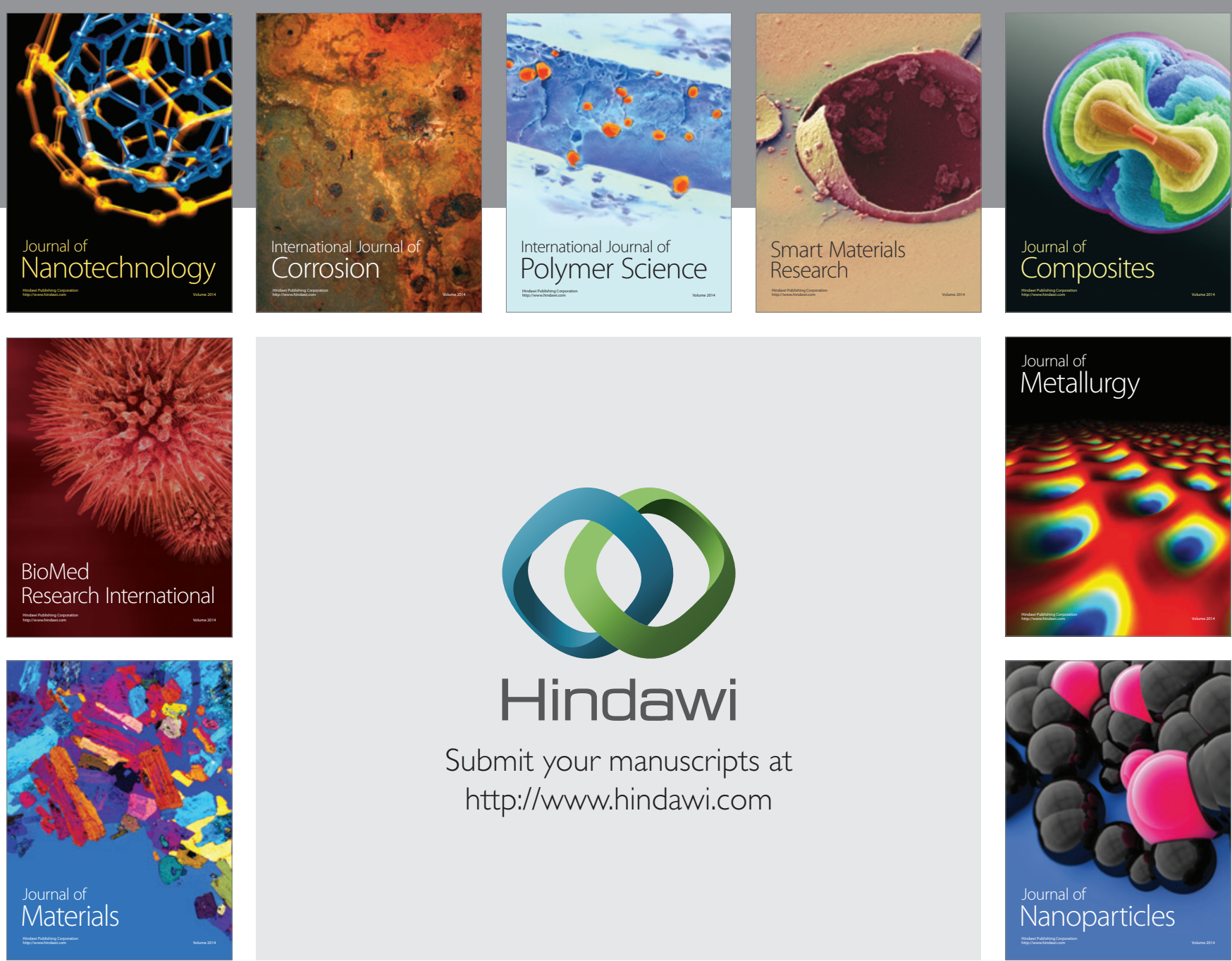

\section{Hindawi}

Submit your manuscripts at

http://www.hindawi.com

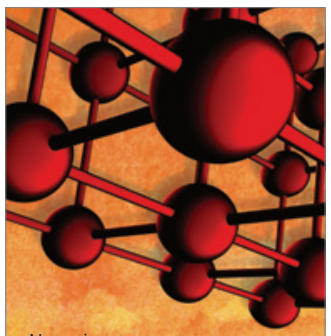

Materials Science and Engineering
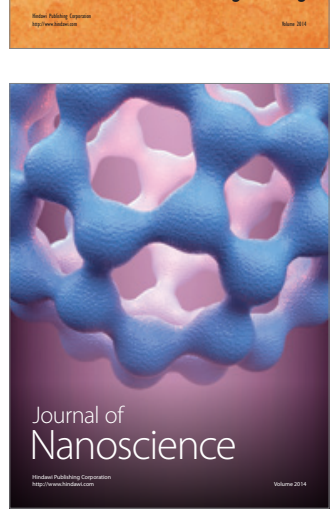
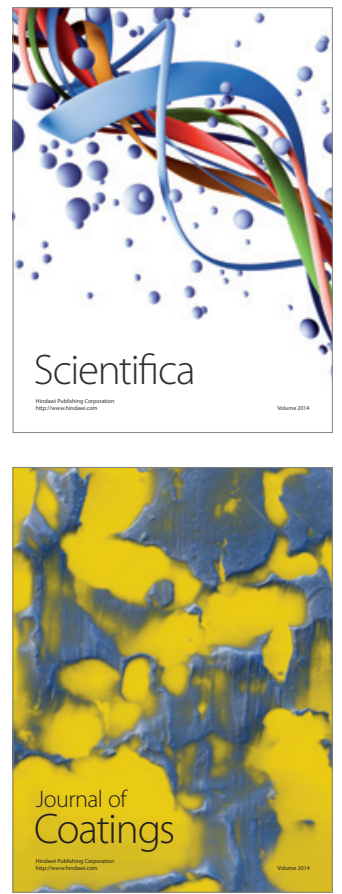
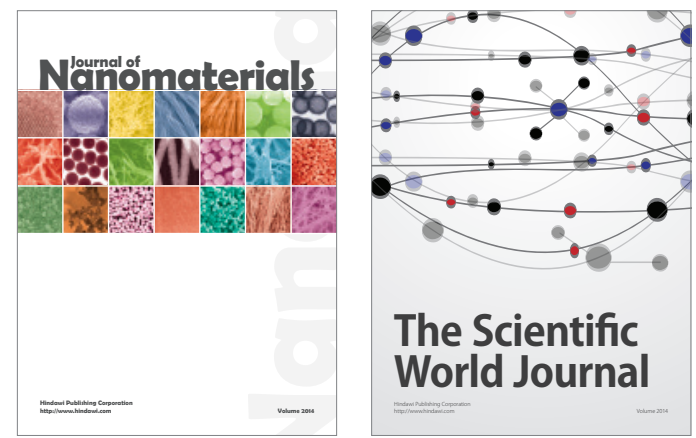

The Scientific World Journal
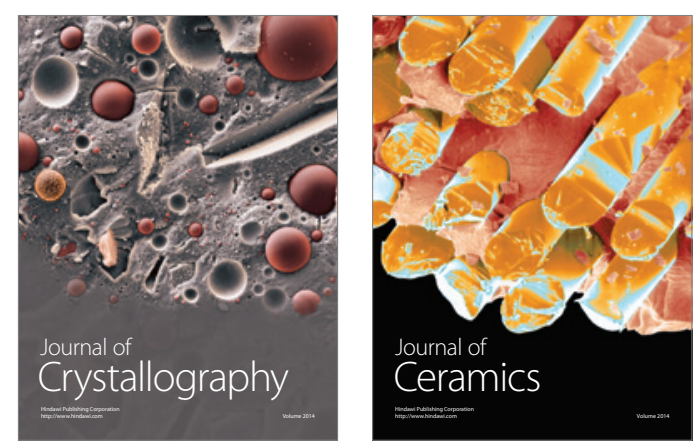
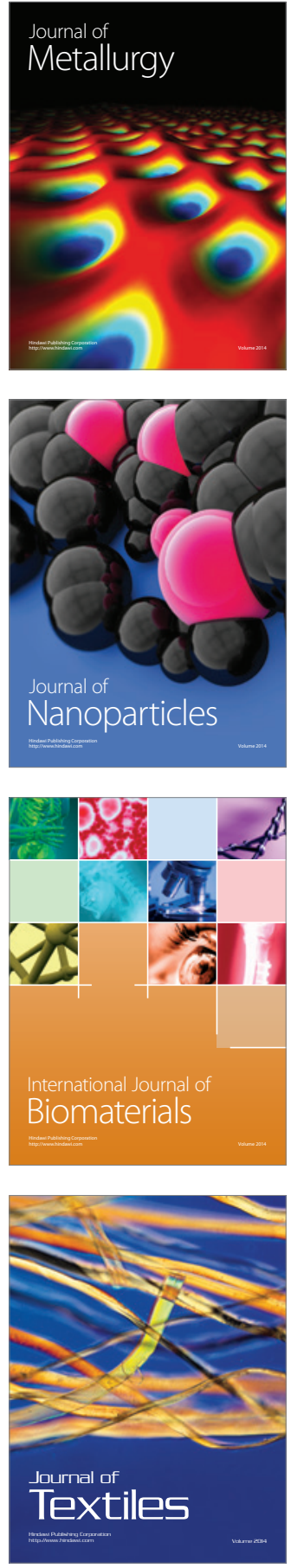